\title{
EDUCAÇÃO AMBIENTAL E SUA RELEVÂNCIA PARA A FORMAÇÃO DO TÉCNICO DA CONSTRUÇÃO CIVIL
}

\author{
Kelly Maria Loureiro Godinho ${ }^{1}$ \\ Pós-graduação Lato Sensu em Proeja, Instituto Federal do Espírito Santo \\ E-mail: kellymarialg@hotmail.com
}

\section{RESUMO}

Artigo oriundo de pesquisa realizada no Curso Técnico em Edificações do Proeja do Instituto Federal do Espírito Santo - Ifes (campus Vitória), centralizada nas práticas educacionais com foco na Educação Ambiental (EA) e serviu para detectar o nível de envolvimento dos alunos com as questões ambientais, revelando seus anseios, dificuldades e os impasses que os professores encontram na Instituição para desenvolver os projetos e, até mesmo, as práticas que envolvam a EA. A abordagem teórica considera o meio ambiente em sua totalidade, levando em conta os aspectos éticos, políticos, econômicos, sociais, culturais, científico-tecnológicos e ecológicos. 0 desenvolvimento da EA, que tem foco a melhoria da qualidade de vida, da sustentabilidade, da saúde humana e ecológica da Terra, faz-se bastante relevante nesse momento histórico de crise ambiental vivido no planeta. Daí a importância de se conscientizar, inserindo a EA na formação intelectual e humana dos profissionais da construção civil.

Palavras-chave: Educação Ambiental. Proeja. Construção Civil.

\section{INTRODUÇÃO}

Atualmente, a questão ambiental apresenta-se revigorada, caracterizando-se por novas e diferentes abordagens. Tem uma preocupação fundamental que se refere ao papel da ciência e das técnicas na construção de novos conceitos e mentalidades, os quais podem contribuir para uma mudança paradigmática do saber. Entretanto, ela não pode estar desvinculada de uma reflexão ampla em torno dos fatores que, historicamente, contribuíram para a produção de uma cultura que pretende, a todo custo, o domínio sobre a natureza. Tal reflexão deve ser crítica em relação às epistemologias que propagam a cisão entre homem e natureza.

O princípio no qual se apoia a relação do homem com o ambiente é o de que a natureza e o ambiente têm valor apenas quando existe algum interesse utilitário envolvido. Assim, em vez de os sujeitos se envolverem com a ideia da natureza e do ambiente como um valor intrínseco, envolvem-se unicamente com a ideia de dominação da natureza, de apropriação dos seus recursos para se atingir determinados fins (BORNHEIM, 1993, apud GAZZINELLI, 2002). Daí surge, de maneira urgente, a necessidade de um gerenciamento dos recursos naturais a partir dos ideais de sustentabilidade ecológica e de equidade social. Para tanto, a educação é condição-chave, sendo fundamental para contribuir com a construção de novas relações de reapropriação do mundo, visando à formação de mentalidades que compreendam as complexas inter-relações do meio para promover ações socioambientais efetivas.

Neste sentido, frequentemente, a Educação Ambiental é apontada como um dos principais caminhos que levam à formação de pessoas capazes de lidar com os problemas e conflitos socioambientais e que estejam preparadas para a compreensão e implementação de debates

\footnotetext{
${ }^{1}$ Geógrafa e Profạ. de Geografia da Rede Municipal de Educação Fundamental de Cariacica, Aluna da Especialização em Proeja do IFES.
} 
científicos e tecnológicos implicados nessas questões. Diante dos problemas socioambientais resultantes das atividades vinculadas à construção civil, sobretudo no meio urbano, onde as

construções se dão de maneira mais densa e os espaços são intensamente ocupados, muitas vezes em discordância com as legislações ambientais vigentes. Diante disso, tornou-se importante e necessário conhecer melhor os conceitos dos diferentes ambientes, as legislações e as alternativas sustentáveis que perpassam as questões ambientais e as atividades da construção civil. Assim, a pesquisa buscou investigar as práticas educacionais da chamada Educação Ambiental (EA) na formação do Técnico de Edificações do Proeja no Instituto Federal de Educação Ciência e Tecnologia do Espírito Santo-Ifes, no Campus Vitória.

Para este estudo, estruturaram-se as seguintes questões: Como a Educação Ambiental está inserida nas aulas do curso de Edificações do Proeja, no Ifes-Vitória? As práticas educativas voltadas para a EA nesse curso contribuem para a formação de profissionais ambientalmente conscientes?

Para responder aos questionamentos propostos, estipulou-se como objetivo geral investigar como a Educação Ambiental vem sendo desenvolvida nas práticas docentes e se essas contribuem para a formação de profissionais ambientalmente conscientes no curso de Edificações do Proeja, no Ifes (Vitória/ES). Para alcance desse objetivo maior, organizaram-se os seguintes objetivos específicos: a) Investigar as práticas educativas dos professores com foco na educação ambiental durante as aulas; b) verificar como a Educação Ambiental está inserida e se ela se dá de forma interdisciplinar e/ou fragmentada; c) e analisar a percepção dos alunos das turmas mais avançadas do curso de Edificações do Proeja a respeito das questões ambientais.

\section{METODOLOGIA}

O caminho metodológico escolhido para obtenção de dados foi o da pesquisa de campo, realizada por meio de questionários aplicados aos alunos/as e professores/as envolvidos/as no curso de Edificações do Proeja, no Ifes, Campus Vitória, bem como o da análise documental. Considerando a classificação de Gil (1999), o estudo caracterizou-se como uma pesquisa descritiva e de tipologia (procedimento) não-experimental.

Em abril de 2010, foram coletadas as opiniões de educandos dos dois últimos módulos (7ํㅜ e 8으) do curso de Edificações do Proeja, totalizando um grupo de 38 alunos. A pretensão foi obter uma pesquisa qualitativa, a partir da qual se buscou verificar o nível de envolvimento dos alunos com as questões ambientais, observar os aprendizados obtidos na sala de aula para resolução de problemas do ponto de vista ambiental e investigar os anseios desses sujeitos quanto à temática aplicada, sobretudo, a sua área de formação profissional.

Com o objetivo de obter dados qualitativos junto aos professores atuantes no curso de Edificações do Proeja, foi elaborado outro questionário que foi aplicado a um grupo de oito docentes, escolhidos aleatoriamente, envolvendo profissionais das coordenadorias de ensino técnico e de ensino básico. A aplicação desses questionários teve como intuito investigar as práticas pedagógicas em relação às questões ambientais, esclarecer as dificuldades e os impasses que os professores encontram na Instituição para desenvolver projetos e, até mesmo, práticas de sala que envolvam a $E A$, além de identificar as suas angústias e os pontos de vistas em relação à EA.

Além dos sujeitos envolvidos, buscou-se analisar o Plano de Curso para Técnico Integrado em Edificações com Ensino Médio para Jovens e Adultos do Ifes. 


\title{
EDUCAÇÃO AMBIENTAL NO PROEJA
}

Atualmente, o Ifes oferta cursos Técnicos Integrados à modalidade de Educação de Jovens e Adultos (PROEJA). O Proeja é um programa do Ministério da Educação para a promoção da formação de jovens e adultos e sua profissionalização, instituído pelo Decreto № 5478 de 24 de junho de 2005. A partir desse Decreto, as instituições que oferecem educação profissional (escolas vinculadas, CEFET's ou Institutos Federais), em todo o país, estão oferecendo cursos que não apenas resgatem a formação para aqueles que perderam a oportunidade de realizá-la no tempo regular, mas que, ao mesmo tempo, garantam sua formação profissional, buscando a inserção no mundo do trabalho.

Conforme consta no Documento base:

A tradição da oferta de cursos de excelência da Rede Federal de Educação Profissional e Tecnológica vem compor com experiências inovadoras na oferta da EJA no Brasil, integrando a educação básica à formação profissional, tendo como produto final uma formação essencialmente integral (BRASIL, 2007 p. 24).

Assim, o Proeja revela a decisão governamental de atender à demanda de jovens e adultos, em geral, excluídos do ensino formal e, por consequência, do trabalho. No documento base que subsidia a organização de propostas consta que "a perspectiva precisa ser, portanto, de formação na vida e para a vida e não apenas a qualificação do mercado ou para ele" (BRASIL, 2007 p.12). Isso representa uma maneira de as escolas de educação profissional desempenhar uma importante função social: formação de técnicos de nível médio oriundos da classe trabalhadora.

Tal perspectiva aponta para a ideia de educação libertadora emancipatória e transformadora, proposta por Paulo Freire, que caminha na direção da Educação Ambiental proposta por Loureiro (2004).

\begin{abstract}
A Educação Ambiental Emancipatória se conjuga a partir de uma matriz que compreende a educação como elemento de transformação social inspirada no diálogo, no exercício da cidadania, no fortalecimento das regras de convívio social, na superação das formas de dominação capitalistas na compreensão do mundo em sua complexidade e da vida em sua totalidade (LOUREIRO, 2004, p.15).
\end{abstract}

Loureiro alerta que EA vai além das ideias de preservação e conservação de ambientes, vindo ao encontro de uma abordagem emancipatória, com vistas à transformação social que supere as relações sociais e de poder impostas pelo modo de produção do capitalismo.

É necessário ir além da concepção de educação que tem como foco principal os recursos naturais, aquela que enfatiza somente as perdas da biodiversidade sem uma visão abrangente. É preciso assumir o enfoque holístico e com a atenção voltada para a complexidade. A educação genuinamente ambiental não pode ser movida por perspectivas baseadas, sobretudo, em análises de custo-benefício, meramente monetárias, em que a natureza se resume a uma grande fábrica.

Seguindo o raciocínio de Bortolozzi (2000), se considerarmos que a ciência nos séculos XVIII e XIX, com a chamada Revolução Industrial, foi tida como forma de conhecimento que traria "progresso", prosperidade e bem-estar aos homens, por outro lado, hoje, a ciência se vê convocada a repensar o seu papel para contribuir na resolução dos problemas de degradação das condições de vida, que esse mesmo modelo de "progresso" criou. E, se não é da competência da ciência decidir sobre o uso das tecnologias que impactam o meio ambiente, porque a decisão é 
muito mais política, caberia a ela, sim, rever o seu papel na busca de um novo paradigma capaz de criar novos valores, pensamentos e ações que possam contribuir para a formação de novas mentalidades, mais aptas a participar de uma política ambiental mais justa.

\footnotetext{
Em nenhum período conhecido da historia humana ela precisou tanto de mudança de paradigma, de uma Educação renovadora, libertadora. Mais do que produzir painéis solares mais baratos, reciclar e dotar os carros de células de combustível, em vez de petróleo, precisamos de um processo mais completo, que promova o desenvolvimento de uma compreensão mais realista do mundo. No século $X X$, o ser humano involuiu, ética e espiritualmente. 0 papel da Educação Ambiental, nesse contexto, torna-se mais urgente. Precisamos oferecer mais formação. A educação ainda "treina" a (o) estudante para ignorar as conseqüências ignorantes de seus atos (DIAS, 2001, p. 16).
}

Para Dias (2001), a Educação Ambiental deve considerar o meio ambiente em sua totalidade (natureza e sociedade), tendo que ser pensada com um processo permanente nos quais os envolvidos, indivíduos e a coletividade, adquiram conhecimento sobre o meio ambiente para que possam agir no sentido de resolver ou, quem sabe, amenizar os problemas ambientais no presente e futuro. Portanto, a EA deve ser abordada cotidianamente nas salas de aula.

\section{A IMPORTÂNCIA E A NECESSIDADE DA EDUCAÇÃo AMBIENTAL NA FORMAÇÃo DO TÉCNICO EM EDIFICAÇÕES}

Em princípio, a relação do homem com o meio ambiente não passava de uma relação de sobrevivência, na qual o homem extraía da natureza o seu próprio sustento. Tratava-se de uma relação que dizia respeito ao modo de viver num mundo cuja natureza era externa e mais poderosa do que os homens e que os afetava mais do que era afetada por eles. Conhecer o meio ambiente consistia numa maneira de se autodefender dos fenômenos da natureza. Porém, a interação entre os homens e o ambiente ultrapassou a questão da simples sobrevivência. Com a urbanização e evolução da civilização humana, a percepção da ambiente mudou drasticamente. Passou a existir o interesse de se explorar o meio ambiente a partir de uma outra visão. Não se tratava mais de retirar da natureza somente o seu próprio sustento; agora, o intuito era criar e produzir utilizando-se de recursos naturais. Com a expansão dessa nova filosofia exploratória, o homem passou a priorizar descobertas que traziam suporte e estrutura ao desenvolvimento.

Assim, "O planeta tem cada vez mais necessidade de pessoas aptas a aprender os problemas fundamentais e globais, e a compreender as realidades complexas, transversais, multidimensionais, globais e planetárias" (MORIN, 2000, apud DIAS, 2001, p.6).

Nesse sentido, é preciso fazer com que a temática ambiental se torne objeto de reflexão e estudo na formação do Técnico em Edificações, entendendo que a educação é fundamental para contribuir para a construção de novas relações de reapropriação do mundo, em vista da formação de profissionais compreensivos ante as complexas inter-relações do meio para ações socioambientais efetivas.

O profissional Técnico em Edificações atua no planejamento e projeto, na execução e na manutenção de obras. As obras, sobretudo as de grande extensão (como estradas, implantação de loteamentos, drenagens, barragens e canais), têm grande impacto sobre o meio ambiente. Além disso, a construção civil consome muitos produtos, cujo consumo agride diretamente a natureza, seja por sua necessidade de extrair e/ou de descartar. Não se pode deixar de citar o consumo de energia e de água e a poluição da atmosfera, sobretudo, por meio dos particulados em suspensão. A manutenção de obras é uma fonte de muitos rejeitos. 
Assim, como aponta o documento dos referenciais curriculares nacionais de Educação Profissional de Nível Técnico da Construção Civil (BRASIL, 2000), a área de construção civil tem uma forte interação com o meio ambiente. Daí a necessidade do curso técnico desta Instituição (ou de qualquer outra) inserir a EA em seu currículo, principalmente, de maneira interdisciplinar.

Acrescentar na formação de profissionais de construção civil a Educação Ambiental como instrumento de conscientização sobre os problemas do meio ambiente, possibilitará a implantação de estratégias mais adequadas e o desenvolvimento de atitudes que possam prevenir os principais impactos ambientais decorrentes de obras.

No entanto, após análise do Plano de Curso para Técnico Integrado em Edificações com Ensino Médio para Jovens e Adultos, do Ifes, constatou-se que na organização curricular do curso as abordagens ambientais não foram contempladas de forma plena. Somente a disciplina de Geografia traz na descrição dos conteúdos programáticos a abordagem das questões ambientais e do desenvolvimento sustentável. A dita disciplina possui carga horária de 135 horas, enquanto a carga horária total do curso é de 2400 horas. De maneira geral, o Plano apresenta a preocupação com a EA, substancialmente, nos itens competências e habilidades elencas para cada módulo (num total de oito). A habilidade que se apresentou mais próxima à EA foi "construir consciência ao meio ambiente".

É necessária a inserção da Educação Ambiental na formação dos profissionais da construção civil, se é que se pretende assumir uma abordagem intrínseca ao conceito de desenvolvimento sustentável, evidenciando a necessidade de construir, criando novas técnicas e respeitando os espaços legalmente protegidos, sem nos autodestruirmos. A preservação do meio ambiente deixou de ser um mero discurso ecológico. Ela representa a sobrevivência do ambiente e dos recursos naturais de que tanto necessitamos.

O ar, a água e o solo são recursos indispensáveis à vida na Terra, pois através de ciclos naturais, os seus constituintes são consumidos e reciclados. A construção civil causa diversos impactos para o meio ambiente, dentre eles, destacam-se: a compactação e impermeabilização do solo, provocando a redução da infiltração da água pluvial no solo; a degradação dos vales fluviais, promovidos por corte das encostas, remoção de sedimentos, aterro e terraplenagem dos fundos de vales; a piora das propriedades físico-químicas do solo pela diminuição da biomassa do mesmo; o aumento de particulados (poeira) no ar; a diminuição da capacidade de recarga hídrica e do nível de água do lençol freático; o assoreamento dos leitos de drenagem naturais e/ou artificiais; a poluição dos recursos hídricos; a diminuição das espécies vegetais, promovida pelos desmatamentos, e a impossibilidade de efetuar a interligação/conexão de fragmentos florestais devido à intensa apropriação dos espaços anteriormente recobertos por eles, trazendo como consequência a redução da oferta de abrigo e alimento à fauna; e a criação de diversos obstáculos para a sustentabilidade dos ecossistemas. Além disso, as atividades de construção civil necessitam dos recursos minerais, energéticos e de água e geram resíduos.

Surge, assim, a necessidade de uma EA voltada para o gerenciamento dos recursos naturais, dos resíduos, dos efluentes, do consumo de água, da minimização da poluição do ar, dos ambientes de preservação, os quais são legalmente protegidos, mas em várias situações desconsiderados.

A Política Nacional de EA (PNEA Lei no 9.795/99), que dispõe sobre a Educação Ambiental em seu art. 2o, diz que " A Educação Ambiental é um componente essencial e permanente da educação nacional, devendo estar presente, de forma articulada, em todos os níveis e modalidades do processo educativo, em caráter formal e não-formal"(BRASIL,1999).

De acordo com a PNEA, a EA é definida como:

Processos por meio dos quais o indivíduo e a coletividade constroem valores sociais, conhecimentos, habilidades, atitudes e competências voltadas para a 
conservação do meio ambiente, bem de uso comum do povo, essencial à sadia qualidade de vida e sua sustentabilidade (BRASIL, Artigo 1ㅇ, 1999).

Essa Política determina que:

A educação ambiental será desenvolvida como uma prática educativa integrada, contínua e permanente em todos os níveis e modalidades do ensino formal. (...) § 3o. Nos cursos de formação e especialização técnico-profissional, em todos os níveis, deve ser incorporado conteúdo que trate da ética ambiental das atividades profissionais a serem desenvolvidas (BRASIL, 1999).

O 2ำ parágrafo do 10 artigo da PNEA determina que "a educação ambiental não deve ser implantada como disciplina específica no currículo de ensino".

Para Fazenda ( 1995 apud DUTRA, 2006, p. 24), conhecimento interdisciplinar busca a totalidade do conhecimento, respeitando-se a especificidade das disciplinas; a escolha de uma bibliografia é sempre provisória, nunca definitiva.

Nesse sentido, o tratamento dado às questões ambientais na tentativa de construir novos conceitos, na formação de cidadãos conscientes e na mudança de atitudes, perpassa por diversas disciplinas, as quais irão contribuir para o tratamento de um tema ou a resolução de um problema, ancorando em suas especificidades, considerando os seus conceitos e métodos.

A educação ambiental deve consolidar-se como uma filosofia de educação, presente em todas as disciplinas existentes e possibilitar uma concepção mais ampla do papel da escola no contexto ecológico local e planetário contemporâneo (BERNARDES, NEHME e COLESANTI, 2005, p. 10).

Essa proposta coincide com as indicações dos Parâmetros Curriculares Nacionais (PCNs) no sentido de abordar a EA como tema transversal, portanto as questões ambientais não devem ficar restritas as áreas de conhecimentos das ciências da natureza ou sociais (como, por exemplo, Biologia e Geografia), mas deve ocorrer como "eixo" transversal as diversas disciplinas, sendo abordada cotidianamente nas salas de aula, uma vez que EA se faz por meio de um processo contínuo (DIAS, 2001), de tomada de consciência gradual, a qual possibilita a intervenção através do desenvolvimento de algumas ações.

De acordo com Raggi, 2003, a EA contribui para integração entre os diversos conteúdos e componentes curriculares, quando propõe o trabalho com temas transversais, interdisciplinares e com projetos. Segundo a autora, o ensino contextualizado e problematizador que se propõe, deve integrar diferentes áreas de conhecimento. Tal integração é possível de ser realizada, desde que ações curriculares sejam planejadas, discutidas e executadas, no sentido de tornarem-se atividades interdisciplinares.

\section{EDUCAÇÃO AMBIENTAL NO CURSO DE EDIFICAÇÕES: O PONTO DE VISTA DE EDUCANDOS E EDUCADORES}

A pesquisa sobre a EA nas instituições escolares é muito relevante para todos os segmentos de ensino, uma vez que, se espera que os atuais educandos, de posse de uma sólida formação ambiental, possam colaborar para um futuro melhor no tocante à conservação dos recursos naturais e para a implantação de alternativas que desempenhem na prática os ideais de um modo de produção sustentável. 


\title{
As opiniões dos/as educandos/as
}

Dos 38 questionários aplicados, 26 foram respondidos por alunos do 70 módulo, e 12 por alunos do 8 o módulo. Desses, $61 \%$ possuem idades entre 19 a 26 anos e somente $16 \%$ estão acima dos 35 anos.

A maioria dos alunos entrevistados (60\%) já atua na área da construção civil, sendo $38 \%$ estagiários.

Quando questionados sobre o que entendem sobre "meio ambiente", alguns alunos/as responderam que este está relacionado com o lugar onde vivemos, sendo "aquilo que está em nossa volta". Outros/as restringiram apenas aos elementos naturais, excluindo os seres humanos do conceito de meio ambiente. E houve aqueles que disseram, ainda, que temos que cuidar e preservar o meio ambiente. De maneira geral, as respostas apareceram bastante tímidas e limitadas e, algumas, apontam sérias deficiências conceituais sobre "meio ambiente" e "preservação".

A maioria dos entrevistados acompanha as questões ambientais por jornais, revistas, noticiários e documentários de TV, totalizando $72 \%$ das respostas.

Para 97\% dos alunos é importante aprender sobre as problemáticas ambientais durante as aulas. Quando perguntados se nas aulas do curso os professores tratam de assuntos que envolvem as questões ambientais, $63 \%$ reconheceram que sim. Tal resultado mostra que possivelmente as abordagens quanto às questões ambientais não se dão de maneira abrangente, pois $37 \%$ dos alunos entrevistados ficam alheios à percepção dessas abordagens.

De acordo com os alunos, as disciplinas que mais abordaram as questões ambientais (Gráfico 01) foram: Projeto Integrador, Instalações Hidrossanitárias, Tecnologias as Construções e SMS, Geografia e Biologia. Vale ressaltar, ainda, que as disciplinas do ensino básico lembradas pelos alunos, ao responderem a essa questão, foram justamente as que abordam a natureza, como Biologia e Geografia.

\section{Gráfico 01 - Disciplinas que envolveram as temáticas ambientais no decorrer do curso de Edificações na opinião dos alunos}

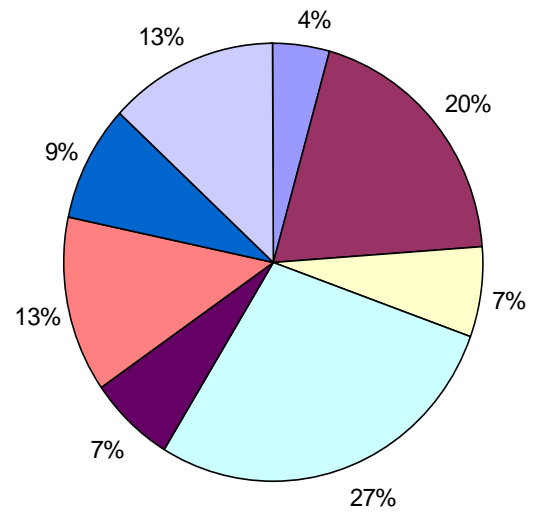

\author{
$\square$ Materiais de construção \\ $\square$ Hidrosanitário \\ $\square$ Tecnologia da construção \\ $\square$ Projeto Integrador \\ Metodologia \\ $\square$ Geografia \\ $\square$ Biologia \\ $\square$ não responderam
}

Segundo as respostas dos alunos, a maioria dos professores trata dos assuntos relacionados às questões ambientais através de visitas técnicas, de textos e de debates (Gráfico 02). 


\title{
Gráfico 02 - Recurso pedagógico utilizado para abordar a questão ambiental na visão dos educandos
}

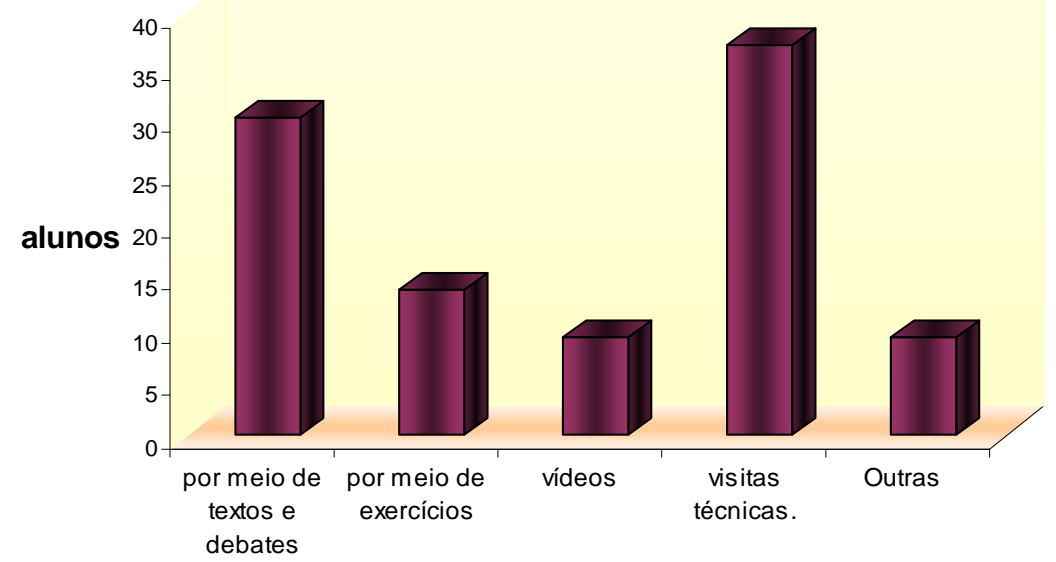

O Gráfico 03 permite constatar que, de maneira geral, não há integração entre os conteúdos de diversas disciplinas com as questões ambientais. Os temas abordados apontam que algumas disciplinas trabalham com as temáticas ambientais com intuito de equacionar problemas específicos, tais como: desperdício de materiais em obras, reutilização e reciclagem de resíduos da construção, casa ecológicas, etc.; outras conceituam e problematizam as questões ambientais existentes no mundo, como a poluição, o aquecimento global, a preservação e conservação dos recursos naturais, etc. Esses apontamentos são importantes, mas precisam ocorrer de maneira integrada e ampla e não de maneira isolada. As diferentes áreas de conhecimento, se trabalhadas juntas, trariam discussão mais abrangentes e soluções mais eficientes. Entretanto, são poucos os professores que, mesmo que isoladamente dedicam parte de seu currículo para as questões ambientais, seja para apresentar o problema, seja para mostrar soluções prontas aos seus alunos/as (como mostra o gráfico 01).

No gráfico 03, pode-se perceber que cada professor (a) escolhe e determina o tema, sem articular com as demais disciplinas. Notou-se a ausência das discussões em relação às legislações pertinentes, sobretudo, no que tange ao uso e ocupação espacial, pensando em inserir obras em concordância com as Leis ambientais e demais normas, o que seria essencial para garantir um desenvolvimento do setor de construção em concordância com a sustentabilidade ambiental.

\section{Gráfico 03 - Manifestações dos alunos referentes aos temas ambientais estudados durante o curso}

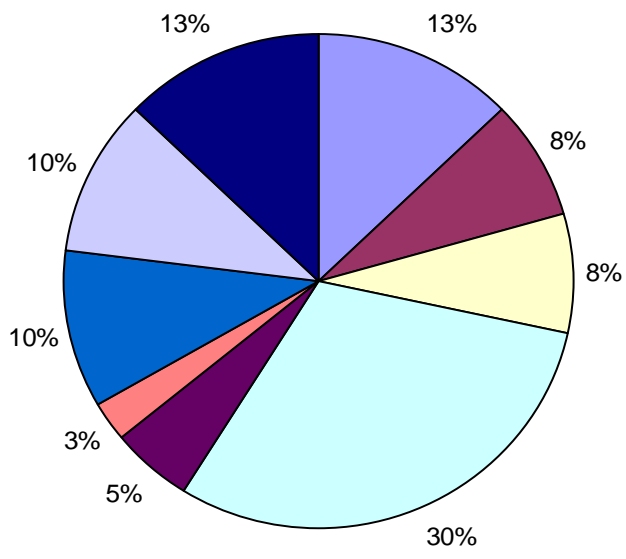

\author{
๑ Tratamento de água e esgoto sanitário \\ $\square$ reciclagem da materiais \\ $\square$ Poluição e Aquecimento global \\ 口 construção sustentável \\ $\square$ reutilização dos materiais de construção \\ $\square$ resíduo das construções \\ - Preservação e conservação dos recursos naturais \\ 口 construção verde e casa ecológica \\ - Não respondeu
}


Porém, diferente do que atualmente ocorre, na concepção da maioria dos alunos (39\%) a Educação Ambiental no Proeja deve ser trabalhada de maneira interdisciplinar.

Para $100 \%$ dos alunos entrevistados, a atividade de construção civil implica em algum problema ambiental. Mas $84 \%$ desses acreditam ser possível haver desenvolvimento no setor de construção civil de maneira sustentável, ou seja, sendo capaz de suprir as necessidades da geração atual sem comprometer a capacidade de atender as necessidades das futuras gerações.

Dentre os principais problemas ambientais gerados pela construção civil, ao responderem esse questionamento, os alunos reconhecem problemas desde o processo de extração da matériaprima até a fase de conclusão da obra. O gráfico 04 indica que $39 \%$ dos alunos destacaram a problemática dos entulhos e resíduos da construção civil como principal problema ambiental. Outros itens apontados pelos alunos mostram os impactos da construção civil sobre os recursos naturais, quando esses se lembraram de problemas como desmatamento, extração de areia, poluição das águas e solo.

\section{Gráfico 04 - Opiniões dos alunos sobre os problemas ambientais promovidos pela construção civil}

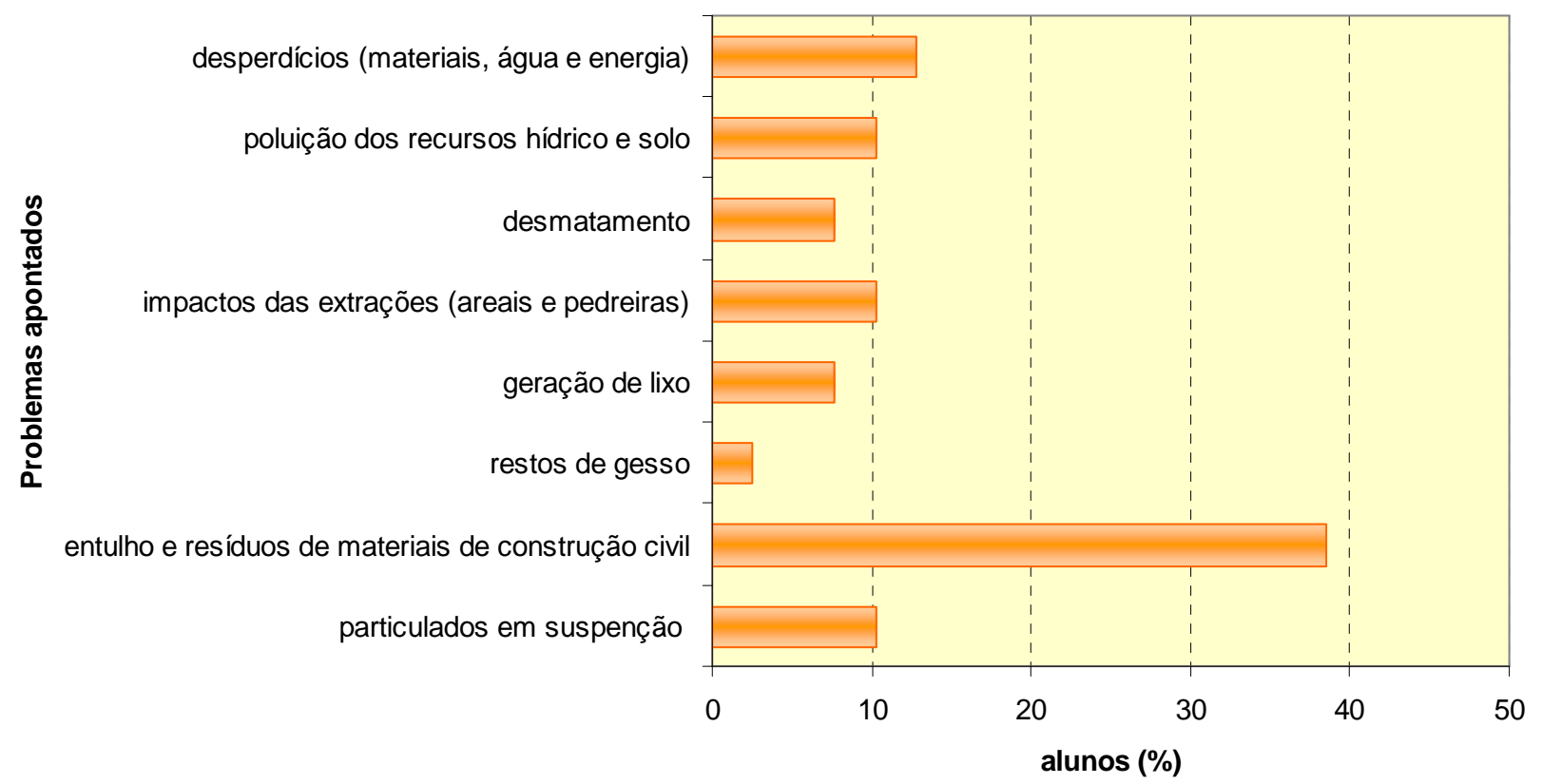

O quadro 1 mostra a opinião dos alunos quanto às temáticas ambientais, as quais consideram de maior relevância e que deveriam ser abordadas nas disciplinas do curso de Construção Civil. Os dados desse quadro revelam as angústias dos alunos quanto à problemática dos resíduos de construção, confirmando ser esse o problema ambiental mais imediato da construção civil na percepção dos discentes, como apontado no gráfico 04.

Os alunos citaram diversos temas, mas observou-se que a principal preocupação está centrada nos recursos naturais como fonte de matéria-prima, nos resíduos da obra e na destinação final. Alguns dos temas citados apontam para a necessidade de os alunos aprenderem a resolver problemas, como a reutilização e a reciclagem dos materiais de obra e entulho. Poucos alunos apontam para a preocupação de conservação do ambiente após a obra, indicando temáticas que promovam a qualidade de uso e ocupação do espaço construído. 


\begin{tabular}{|l|c|}
\hline \multicolumn{1}{|c|}{ Opinião dos alunos } & $\begin{array}{c}\text { Alunos } \\
\text { (\%) }\end{array}$ \\
\hline Resíduo de materiais da construção civil & 13 \\
\hline Entulho & 7 \\
\hline Lixo & 4 \\
\hline Meio Ambiente e construção sustentável & 16 \\
\hline Preservação e conservação dos recursos naturais & 4 \\
\hline Reutilização e Reciclagem de materiais de obra e entulho & 19 \\
\hline Desperdícios & 7 \\
\hline Economia de energia e água & 10 \\
\hline Desmatamento para construção e as ocupações de áreas inadequadas & 4 \\
\hline Tratamento de esgoto & 1 \\
\hline Não respondeu & 10 \\
\hline
\end{tabular}

Quadro 01 - Opiniões dos alunos sobre as temáticas ambientais de maior relevância a serem abordadas nas disciplinas do curso de edificações

\section{A visão dos/as educadores/as}

Dos oito professores que responderam ao questionário, somente $37 \%$ possuem experiência de atuação na Educação Ambiental.

Embora $100 \%$ dos profissionais tenham respondido que ocorre integração entre os conteúdos curriculares da sua disciplina com a temática ambiental e que consideram relevante a EA na formação técnica da construção civil, somente 1 (um) professor admitiu estar trabalhando com alguma temática voltada à questão ambiental, mas que essa ocorre de maneira fragmentada, não fazendo parte de nenhum projeto interdisciplinar.

Coincidindo com as respostas dos alunos, o gráfico 05 mostra que as questões ambientais (problemas e conceitos) mais abordadas pelos professores no curso são referentes aos resíduos de construção.

Gráfico 5 - Temas ambientais trabalhados pelos professores com os alunos do PROEJA
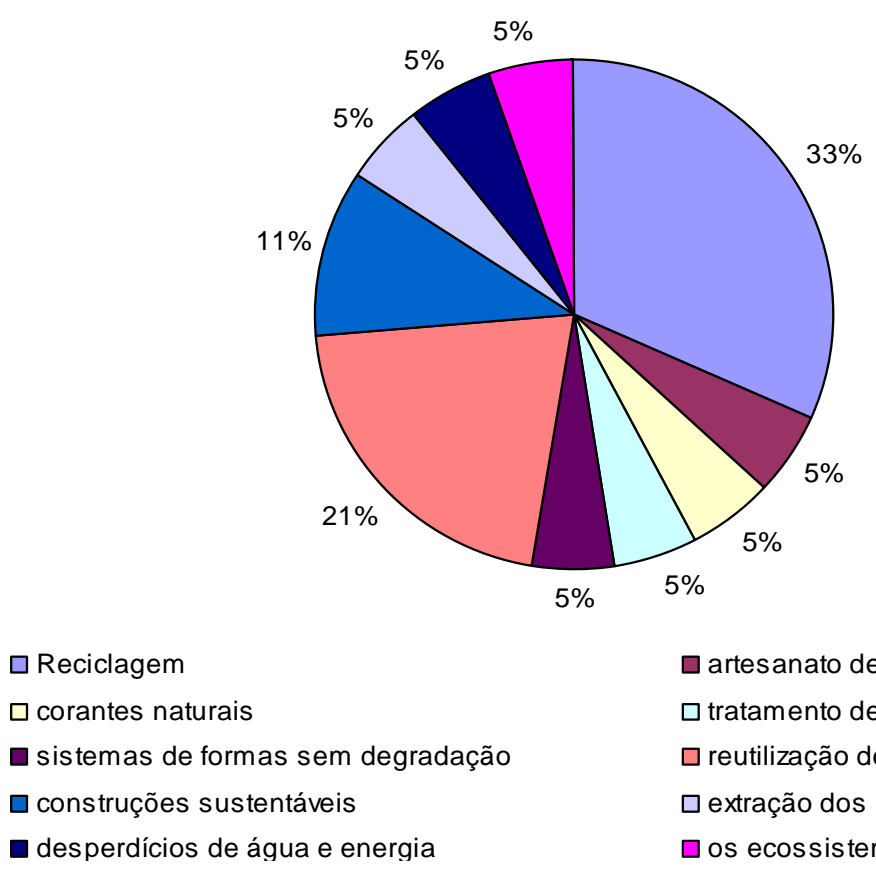
Dentre as temáticas ambientais que os/as educadores/as consideram mais relevantes para a formação do técnico em construção civil, sendo apontadas no gráfico 06, os resíduos de construção civil são mais uma vez destacados pela maioria dos entrevistados.

\title{
Gráfico 06 - Temáticas ambientais apontadas pelos professores como relevantes para a formação dos
} profissionais da construção civil

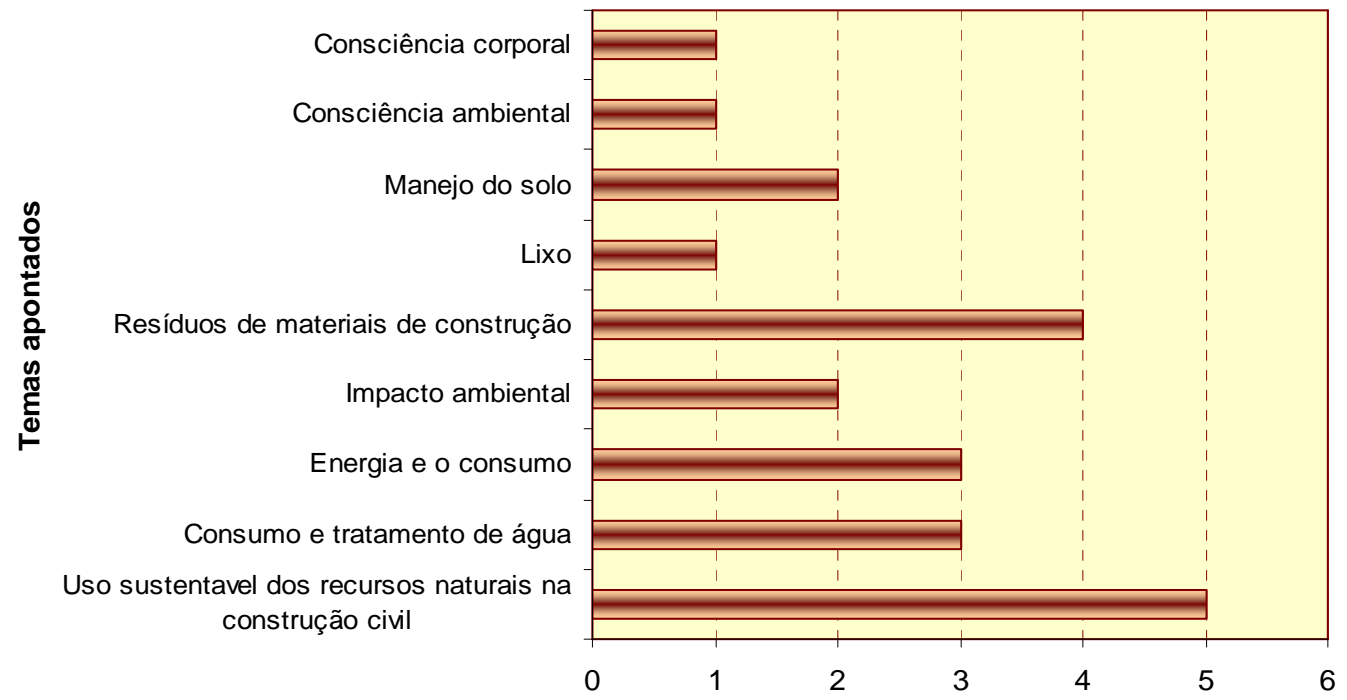

Para a maioria dos professores $(62,5 \%)$ entrevistados, a EA no Proeja deve ocorrer de maneira interdisciplinar. Porém, quando questionados se costumam trabalhar a EA nessa perspectiva, somente $38 \%$ afirmaram que sim.

O gráfico 07 mostra que os principais obstáculos apontados pelos professores para desenvolver a EA de maneira interdisciplinar no curso de Construção Civil do Proeja são: o apoio pedagógico, o curto tempo de aula para a quantidade de conteúdos curriculares exigidos e a dificuldade de planejamento em conjunto.

\section{Gráfico 07 - Fatores que dificultam o desenvolvimento da EA de maneira interdisciplinar no IFES, na opinião dos professores}

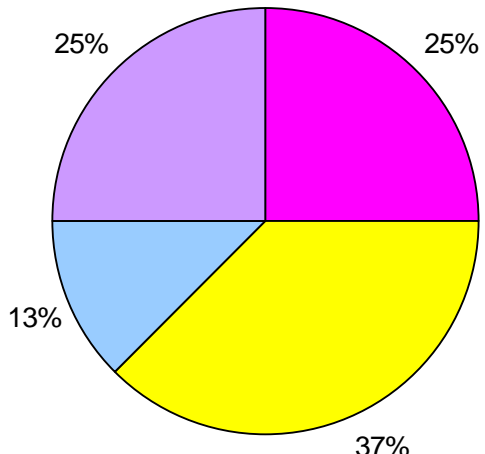

\author{
curto tempo para tanto \\ conteúdo \\ $\square$ apoio pedagógico \\ $\square$ falta de diálogo e boa \\ vontade \\ $\square$ planejamento em conjunto
}

Todos os professores pesquisados consideram necessário o seu aperfeiçoamento em forma de capacitação e/ou curso de atualização para o desenvolvimento de temáticas de EA nas práticas de 
sala de aula. Dos entrevistados, 38\% já participaram de algum curso de aperfeiçoamento ou especialização na área ambiental, sendo que $25 \%$ participaram de cursos nessa área ofertados pelo Ifes.

Assim como para a maioria dos alunos, a maneira como acompanham as questões ambientais ocorrem com maior frequência por meio de jornais, revistas, noticiários e documentários de TV, sendo as opções para $56 \%$ dos professores entrevistados.

\section{CONCLUSÕES}

De forma geral, os resultados obtidos permitiram observar que há reduzida preocupação com as questões ambientais referentes aos conhecimentos sobre os ecossistemas, equilíbrios biológico e cíclico da fauna e flora; sobre os ambientes físicos (rocha, estrutura do solo, água, etc.), que em muito são alterados nos processos de construção e ocupação; sobre as restrições legais referentes aos espaços protegidos; bem como sobre as alternativas para evitar e/ou reduzir os impactos ambientais promovidos pelas obras.

A pesquisa apontou que as abordagens realizadas no tocante às questões ambientais buscam, com algumas soluções técnicas conservacionistas, resolver de forma simplista problemas ambientais complexos. Entre elas, foram apontados: reutilização e reciclagem de resíduos da construção civil, construção verde, casas ecológicas, poluição e aquecimento global, lixo e outras

Tais abordagens revelam uma visão reducionista dos problemas, sem uma contextualização histórico-social-espacial desses problemas, ignorando completamente uma discussão com os educandos sobre as causas. Isso não significa dizer que essas soluções técnicas não sejam necessárias, mas apenas que, se as práticas escolares consideradas de EA não forem redimensionadas de forma mais abrangente e integradora no ensino, tornam-se práticas escolares pouco conscientizadoras, não permitindo aos educandos a compreensão globalizante da problemática ambiental. Essas práticas não são vistas como atividades formadoras de conceitos e valores que apontam para uma sensibilização e uma mudança paradigmática do saber.

A EA está presente de maneira limitada e fragmentada nas práticas educativas do curso de Edificações do Proeja. Nessas práticas não contribuem para que ocorra a integração entre os diversos conteúdos e componentes curriculares com a EA, pois, no geral, os trabalhos não são propostos de maneira interdisciplinar e com projetos, como Raggi defendeu em sua dissertação (2003).

Diferente do que defendem Dias, Loureiro, Freire e outros, a maneira como as questões ambientais vêm sendo desenvolvidas nas aulas do curso de Edificações do Proeja (Ifes) não implicam adequadas condições capazes de levar os educandos ao encontro da EA efetiva, sensibilizadora, conscientizadora, emancipatória e transformadora.

Embora existam instrumentos legais que determinem a presença da EA em todos os níveis de ensino, considerando, ainda, como tema transversal, a pesquisa mostrou que, não diferente do que ocorre em diversas instituições de ensino, na prática a legislação não vem sendo cumprida. Diversos obstáculos apontados pelos profissionais dificultam a implantação efetiva da $E A$, tais como: falta de capacitação, falta de apoio pedagógico, falta de tempo de planejamento conjunto entre os/as professores/as de diferentes disciplinas, os extensos conteúdos curriculares obrigatórios para o curto tempo dado para a disciplina, dentre outros.

O/a professor/a tem papel fundamental para que a EA aconteça no decorrer do curso, pois é atuante direto no processo de inclusão da dimensão ambiental no ensino profissionalizante. É ele ou ela, dentro de sua área de conhecimento, que terão envergadura para propor um aprofundamento teórico/prático nas questões ambientais, considerando o ambiente escolar e o cotidiano de seus alunos/as. Entretanto, os sujeitos entrevistados apontaram para a necessidade de capacitações - não se considerando amplamente preparados para trabalhar com temáticas 
ambientais -, de apoio pedagógico, sobretudo, para trabalhar de maneira interdisciplinar e de planejamentos em conjunto com professores/as de outras coordenadorias.

A instituição deve propiciar às/aos docentes e às/aos discentes novos contextos cognitivos, que abordem uma nova ética na relação sociedade-natureza, garantindo a formação de cidadãos conhecedores dos problemas da sociedade brasileira nos aspectos econômicos, políticos, sociais, culturais e ambientais, transformadores, capazes de interferir positivamente para resolução desses problemas.

A Instituição deve garantir uma Educação Ambiental permanente e concebida em bases interdisciplinares, considerando a aquisição de conhecimentos, valores, habilidades e experiências ligadas ao meio ambiente, bem como elaborar e implantar um programa que contemple diversas estratégias e projetos específicos para educar profissionais, a fim de sensibilizá-los para novas posturas pessoais, tornando-os multiplicadores dessas novas práticas no trabalho, em casa e na comunidade.

\section{REFERÊNCIAS}

BERNARDES, Maria B J; COLESANTI, Marlene T de M; NEHME, Valéria Guimarães de F. A crise ambiental: um breve resgate. Enciclopédia Bioesfera, N01, 2005. Disponível em: www.conhecer.org.br/enciclop/2005/20053a.pdf - Acesso: 06 de Junho de 2009.

BORTOLOZZI, Arlêude. Diagnóstico da Educação Ambiental no Ensino de Geografia. Cadernos de Pesquisa. São Paulo, mar. 2000. Disponível em: www.scielo.br/pdf/cp/ n109/n109a07.pdf. Acesso: 04 de Junho de 2009.

BRASIL. Decreto no 5.478 de 24/06/2005. Institui, no âmbito das instituições federais de educação tecnológica, o Programa de Integração da Educação Profissional ao Ensino Médio na Modalidade de Educação de Jovens e Adultos - PROEJA. Disponível em: http://www.datadez.com.br/content/ legislacao.asp?id=11875. Acesso em 08 de Junho de 2009.

BRASIL. Lei n. 9.795, 27 abr. 1999. Dispõe sobre a Educação Ambiental, institui a Política Nacional de Educação Ambiental e dá outras providências. Diário Oficial, Brasília, 28 abr. 1999.

BRASIL. Ministério da Educação. Leis de Diretrizes e Bases da Educação Nacional. Brasília: $\mathrm{MEC} / \mathrm{SEF}, 1996$.

BRASIL. Ministério da Educação. Parâmetros Curriculares Nacionais. v. I, II e III. Brasília/DF: SEMTEC, 1999.

BRASIL. Ministério da Educação. Referenciais curriculares nacionais da educação profissional de nível técnico. Área profissional: Construção Civil. Brasília, 2000.

BRASIL. Ministério da Educação. Documento Base: Programa Nacional de Integração da Educação Profissional com a Educação Básica na Modalidade de Educação de Jovens e Adultos. Brasília, 2007. Disponível em http://portal.mec.gov.br/setec/aquivos/pdf/documento_base.pdf. Acesso em 08 de abril de 2010.

DIAS, Genebaldo Freire. Educação Ambiental: princípios e práticas 7ạ. Edição. São Paulo: Gaia, 2001. 
DUTRA, José Henderson Fonseca. A educação ambiental no ensino Profissionalizante: Uma Reflexão Baseada em Estudo Desenvolvido no Centro Federal de Educação Tecnológica - Unidade Descentralizada de Leopoldina (MG). Dissertação (mestrado) - Universidade de Taubaté. São Paulo, 2006. Disponível em: http://www.ufmt.br/gpea/pub/hernderson\%20dutra_ dissertacao.pdf=. Acesso em 15 de maio de 2010.

FREIRE, Paulo. Pedagogia da Autonomia: Saberes Necessários à Prática Educativa. 35. ed. São Paulo: Paz e Terra.

GAZZINELLI, Maria Flávia. Representações do Professor e Implementação de Currículo de Educação Ambiental. Cadernos de Pesquisa, n. 115, março/ 2002 p. 173-194. Disponível em: http://www.scielo.br/pdf/cp/n115/a07n115.pdf Acesso em 18 de maio de 2010.

GIL, Antonio Carlos. Métodos e técnicas de pesquisa social. São Paulo: Atlas, 1999.

LOUREIRO, Carlos F.B.; ALBUQUeRQUE, Eliana C.P.T.de; BARRETO, Betânia M. V. B. Sustentabilidade, exclusão e transformação social: contribuições à reflexão crítica da Educação Ambiental e da comunicação no Brasil. Revista Ambiente \& Educação. Vol. 9. Rio Grande: FURG, 2004.

LOUREIRO, Carlos Frederico B. Trajetória e Fundamentos da Educação Ambiental. São Paulo: Cortez, 2004.

RAGGI, D.Gonçalves. Sistema de ações para introdução da educação ambiental no processo pedagógico do Ensino. 